\title{
Somatostatin and dopamine receptor interaction in prostate and lung cancer cell lines
}

\author{
M Arvigo*, F Gatto*, M Ruscica', P Ameri, E Dozio² ${ }^{2}$ M Albertelli, M D Culler ${ }^{3}$, M Motta ${ }^{1}$, F Minuto, \\ P Magni ${ }^{1}$ and D Ferone
}

Department of Endocrinological and Medical Sciences and Center of Excellence for Biomedical Research, Università degli Studi di Genova, 16132 Genova, Italy

${ }^{1}$ Department of Endocrinology, Pathophysiology and Applied Biology and ${ }^{2}$ Department of Human Morphology and Biomedical Sciences 'Citta' Studi',

Università degli Studi di Milano, 20133 Milan, Italy

${ }^{3}$ Biomeasure Incorporated/IPSEN, Milford, Massachusetts, 1757 USA

(Correspondence should be addressed to D Ferone; Email: ferone@unige.it)

*(M Arvigo and F Gatto contributed equally to this work)

\begin{abstract}
Somatostatin analogues inhibit in vitro cell proliferation via specific membrane receptors (SSTRs). Recent studies on transfected cell lines have shown a ligand-induced formation of receptor dimers. The aim of this study is 1) to evaluate the role of specific ligands in modulating receptor interactions in the androgen-dependent prostate cancer cell line, LNCaP, and in the non-small cell lung cancer line, Calu- 6 , by co-immunoprecipitation and immunoblot; and 2) to correlate the antiproliferative effect of these compounds with their ability in modulating receptor interactions. In LNCaP, we have demonstrated the constitutive presence of $\operatorname{sstr}_{1} / \mathrm{sstr}_{2}, \mathrm{sstr}_{2} / \mathrm{sstr}_{5}, \mathrm{sstr}_{5} /$ dopamine (DA) type 2 receptor $\left(\mathrm{D}_{2} \mathrm{R}\right)$, and $\operatorname{sstr}_{2} / \mathrm{D}_{2} \mathrm{R}$ dimers. BIM23704 (sstr ${ }_{1}$ - and sstr $_{2}$-preferential compound) increased the co-immunoprecipitation of $\operatorname{sstr}_{1} / \mathrm{sstr}_{2}$ and significantly inhibited proliferation (-30.98\%). BIM-23244 (str $2-$ sstr $_{5}$ selective agonist) significantly increased the co-immunoprecipitation of $\operatorname{sstr}_{2} / \mathrm{sstr}_{5}$, and induced a $-41 \cdot 36 \%$ inhibition of proliferation. BIM-23A760, a new somatostatin/DA

chimeric agonist with a high affinity for $\operatorname{sstr}_{2}$ and $\mathrm{D}_{2} \mathrm{R}$ and a moderate affinity for $\operatorname{sstr}_{5}$, significantly increased the $\operatorname{sstr}_{5} / \mathrm{D}_{2} \mathrm{R}$ and $\operatorname{sstr}_{2} / \mathrm{D}_{2} \mathrm{R}$ complexes and was the most powerful in inhibiting proliferation $(-42 \cdot 30 \%)$. The chimeric compound was also the most efficient in modulating receptor interaction in Calu- 6 , increasing the co-immunoprecipitation of $\mathrm{D}_{2} \mathrm{R} / \mathrm{sstr}_{5}$ and inhibiting cell proliferation $(-30 \cdot 54 \%)$. However, behind BIM-23A760, BIM-53097 ( $\mathrm{D}_{2} \mathrm{R}$-preferential compound) also significantly inhibited Calu-6 proliferation $(-17 \cdot 71 \%)$, suggesting a key role for $\mathrm{D}_{2} \mathrm{R}$ in receptor cross talk and in controlling cell growth. Indeed, activation of monomeric receptors did not affect receptor co-immunoprecipitation, whereas cell proliferation was significantly inhibited when the receptors were synergistically activated. In conclusion, our data show a dynamic ligand-induced somatostatin and DA receptor interaction, which may be crucial for the antiproliferative effects of the new analogues.

Journal of Endocrinology (2010) 207, 309-317
\end{abstract}

\section{Introduction}

Somatostatin (or somatotropin release-inhibiting factor, SRIF) acts through five specific G-protein-coupled membrane receptors (SSTRs), code named sstr $_{1-5}$, expressed in SRIFtarget cells (Patel 1999, Møller et al. 2003). SRIF mainly exerts an inhibitory effect on cell functions, such as secretion and proliferation (Lamberts et al. 2002). The inhibitory activity of SRIF is replicated by the SRIF analogues octreotide and lanreotide, already used in the clinical practice to control hormonal hypersecretion by the pathological tissues highly expressing sstr ${ }_{2}$, such as $\mathrm{GH}$-producing pituitary adenomas or certain neuroendocrine tumors (Weckbecker et al. 2003). The stimulation of SSTRs by SRIF analogues may also produce an antiproliferative effect in vitro, due to either cell cycle arrest or

induction of apoptosis (Danila et al. 2001, Ferone et al. 2002, Ferrante et al. 2006, Florio 2008).

In the past years, the knowledge about SSTRs physiopathology has been extended by the discovery that SSTRs can interact on cell membrane forming receptor dimers (Rocheville et al. 2000a). A series of studies, carried out on transfected cell lines, have shown that dimers can consist of two identical SSTR subtypes (homodimers) or two different subtypes (heterodimers), with a range of possible combinations depending on the specific subtype and, probably, on the specific SSTR-expressing cell population. SSTR dimerization can be a ligand-dependent phenomenon, since natural SRIF and subtype-specific SRIF agonists have different effects on dimerization, leading to formation or, on the contrary, dissociation of SSTR dimers (Rocheville et al. 2000a, 
Pfeiffer et al. 2001, Patel et al. 2002, Grant et al. 2004a,b, 2008). SSTR homo- and heterodimerization also involve cellular events beyond the membrane, since it modifies SSTR internalization and trafficking (Baragli et al. 2007), as well as signal transduction (Kidd et al. 2008). SSTRs can also heterodimerize with other G-protein-coupled receptors, such as the $\mu$-opioid receptor (Pfeiffer et al. 2002) and dopamine (DA) type 2 receptor $\left(\mathrm{D}_{2} \mathrm{R}\right.$; Rocheville et al. $2000 \mathrm{~b}$, Baragli et al. 2007).

The heterodimerization of these G-protein-coupled receptors and the related cellular events open a new possible scenario in the field of treatments targeting SSTR-expressing tumors (Papotti et al. 2002). In fact, new SRIF analogues, which bind more than one SSTR subtype (Weckbecker et al. 2003) and chimeric compounds binding SSTRs and $\mathrm{D}_{2} \mathrm{R}$, have been developed and are now available for phase 2 studies (Ferone et al. 2007). Indeed, SSTRs and $\mathrm{D}_{2} \mathrm{R}$ are frequently co-expressed in those diseases for which therapies with SRIF analogues have already been approved (O'Toole et al. 2006, Ferone et al. 2008, Srirajaskanthan et al. 2009). However, only few studies have been performed to evaluate the final consequences of G-protein-coupled receptors dimerization on cell functions so far (Ferone et al. 2005, Grant et al. 2008), and the clinical relevance of SSTR and $\mathrm{D}_{2} \mathrm{R}$ heterodimerization must be proved.

In this study, we analyzed the effects of different SRIF analogues and of one SRIF/DA chimeric compound on SSTRs and $\mathrm{D}_{2} \mathrm{R}$ interaction on cell membrane and cell proliferation in a cell line constitutively expressing four out of five SSTRs, the androgen-dependent prostate cancer cell line LNCaP (Ruscica et al. 2010), and in a cell line constitutively expressing three out of four SSTRs and the $\mathrm{D}_{2} \mathrm{R}$, the non-small cell lung cancer (NSCLC) line Calu-6 (Ferone et al. 2005).

\section{Materials and Methods}

\section{Cell cultures}

Human androgen-dependent prostate cancer (LNCaP) and NSCLC (Calu-6) lines, both from American Type Culture Collection (Rockville, MD, USA), were grown at $37^{\circ} \mathrm{C}$ in a humidified $\mathrm{CO}_{2}$ incubator in monolayer. The culture media were RPMI 1640 supplemented with $10 \mathrm{mg} / 1$ phenol red, and 10\% FBS for LNCaP and MEM supplemented with $10 \%$ FBS, $1 \%$ non-essential amino acids, $20 \mathrm{mg} / \mathrm{dl}$ gentamycin, $200 \mathrm{mM}$ glutamine, and $1 \mathrm{mM}$ sodium pyruvate for Calu-6 cells. Subconfluent cells were collected with $0 \cdot 05 \%$ trypsin/0.02\% EDTA (Biochrom, Berlin, Germany) and were seeded into $150 \mathrm{~cm}^{2}$ flasks or in 96-well plates depending on the experiments.

\section{Products}

The SRIF analogues lanreotide (BIM-23014), the bi-specific sstr $_{2} /$ sstr $_{5}$-preferential compound BIM-23244, the sstr $_{2}-$ preferential compound BIM-23120, the sstr $_{5}$-preferential compound BIM-23206, the $\operatorname{sstr}_{1}$-preferential compound BIM-23926, the bi-specific sstr 1 / sstr $_{2}$-preferential compound BIM-23704 with a relative lower affinity for $\mathrm{sstr}_{3}$, the $\operatorname{sstr}_{2} / \mathrm{sstr}_{5} / \mathrm{D}_{2} \mathrm{R}$ chimeric compound BIM-23A760, and the $\mathrm{D}_{2} \mathrm{R}$-preferential compound BIM-53097 were used in this study and their respective affinities $\left(K_{\mathrm{i}}\right)$ are listed in Table 1. All experimental compounds were kindly provided by IPSEN/Biomeasure (Milford, MA, USA).

\section{$R N A$ extraction and reverse transcription-PCR analysis}

For RNA studies, cells were washed with cold PBS, collected, snap-frozen in liquid nitrogen, and stored at $-80{ }^{\circ} \mathrm{C}$ until RNA extraction. Non-functional pituitary adenoma, obtained from surgery, was taken as positive controls. Total cellular RNA was extracted with the phenol-chloroform method using the Tri Reagent solution (Sigma-Aldrich). Reverse transcription (RT)-PCR analysis for the expression of gene coding for $\mathrm{D}_{2} \mathrm{R}$ was performed on total RNA samples. The RT reaction was carried out in a $20 \mu$ volume, using a commercially available kit (Superscript VILO cDNA Synthesis kit; Invitrogen). The primers used to detect the expression of human $\mathrm{D}_{2} \mathrm{R}$ mRNA were as follows: forward $\left(5^{\prime}-\mathrm{gCg}\right.$ gAC AgA CCC CAC TAC AA-3') and reverse $\left(5^{\prime}-\mathrm{AAg}\right.$ ggC ACg Tag AAg gAg AC-3').

Table 1 Human dopamine $\left(D_{2} R\right)$ and somatostatin receptor (SSTR)-binding affinities of the analogues used in this study compared with the SRIF. Bold values represent the highest affinity values of each compound for the respective receptor subtype(s)

\begin{tabular}{|c|c|c|c|c|c|c|}
\hline Ligands & sstr $_{1}$ & sstr $_{2}$ & sstr $_{3}$ & sstr $_{4}$ & sstr $_{5}$ & $D_{2} R$ \\
\hline SRIF-14 & $1 \cdot 9$ & $0 \cdot 2$ & $1 \cdot 2$ & $1 \cdot 7$ & $1 \cdot 4$ & - \\
\hline BIM-23014 & 2129 & $0 \cdot 75$ & 98 & 1826 & $12 \cdot 7$ & - \\
\hline BIM-23244 & 1020 & $0 \cdot 29$ & 133 & 1000 & $0 \cdot 67$ & - \\
\hline BIM-23120 & 1000 & $0 \cdot 34$ & 412 & 1000 & $213 \cdot 5$ & - \\
\hline BIM-23704 & $6 \cdot 25$ & $1 \cdot 37$ & $43 \cdot 2$ & 1000 & 115 & - \\
\hline BIM-23296 & $3 \cdot 6$ & $>1000$ & $>1000$ & 833 & 788 & - \\
\hline BIM-53097 & - & - & - & - & - & $22 \cdot 1$ \\
\hline BIM-23206 & 1152 & 166 & 1000 & 1618 & $2 \cdot 4$ & - \\
\hline BIM-23A760 & 622 & $0 \cdot 03$ & 160 & 1000 & 42 & 15 \\
\hline
\end{tabular}




\section{Membrane protein extraction}

For membrane protein extraction, $5 \times 10^{6}$ cells from both the cell lines were seeded into $150 \mathrm{~cm}^{2}$ flasks in the appropriate culture media. After $24 \mathrm{~h}$ of starvation in serum-free media, the culture medium was replaced by adding the experimental medium containing somatostatin analogues (concentration $10^{-9} \mathrm{M}$ ). After a $24 \mathrm{~h}$ incubation, LNCaP and Calu-6 were solubilized in lysis buffer (20 mM HEPES, $5 \mathrm{mM}$ EDTA, $3 \mathrm{mM}$ EGTA, $150 \mathrm{mM} \mathrm{NaCl}, 1 \mathrm{mM}$ phenylmethylsulphonyl fluoride, $10 \mu \mathrm{g} / \mathrm{ml}$ soybean trypsin inhibitor, $10 \mu \mathrm{g} / \mathrm{ml}$ leupeptin, and $50 \mu \mathrm{g} / \mathrm{ml}$ bacitracin) and subsequently centrifuged at $20000 \mathrm{~g}$. Membrane pellet was resuspended with lysis buffer combined with $4 \mathrm{mg} / \mathrm{ml}$ dodecyl-D-maltoside, incubated for $1 \mathrm{~h}$ on ice, and centrifuged at $20000 \mathrm{~g}$ at $4{ }^{\circ} \mathrm{C}$. Glycosylated proteins were immobilized by recycling the solubilized membrane proteins of the supernatant through a $0.5 \mathrm{ml}$ wheat germ agglutinin (Vector Laboratories, Burlingame, CA, USA) column overnight at $4{ }^{\circ} \mathrm{C}$. The column was eluted with lysis buffer containing $3 \mathrm{mM}$ $N, N^{\prime}, N$-triacetylchitotriose (Sigma-Aldrich). The protein content of the eluted protein was assessed by Bio-Rad Protein assay (Bio-Rad).

\section{Immunoblot analysis}

For $\mathrm{D}_{2} \mathrm{R}$, sstr ${ }_{1}$, and $\operatorname{sstr}_{5}$ protein detection and for dimerization studies, $100 \mu \mathrm{g}$ of LNCaP and Calu-6 membrane receptors and the supernatants obtained after immunoprecipitation were fractioned on $12.5 \%$ SDS-PAGE and were electrophoretically transferred to Hybond-C extra nitrocellulose membrane (GE Healthcare, Chalfont, St Giles, UK). Non-specific binding sites were blocked by treating the membranes with Tris-buffered saline-Tween (TBS-T: 0.02 M Tris, 0.137 M $\mathrm{NaCl}$, and $0 \cdot 5 \%$ Tween $20 ; \mathrm{pH} 7 \cdot 6$ with $1 \mathrm{M} \mathrm{HCl}$ ) containing $5 \%$ non-fat dried milk for $1 \mathrm{~h}$ at $22{ }^{\circ} \mathrm{C}$ on a rotating shaker. After three washes with TBS-T, membranes were incubated for $16 \mathrm{~h}$ at $4{ }^{\circ} \mathrm{C}$ with a $1: 500$ dilution of mouse anti-human $\mathrm{D}_{2} \mathrm{R}$ monoclonal antibody, rabbit anti-human sstr $_{1}$ polyclonal antibody, rabbit anti-human sstr 2 polyclonal antibody, rabbit anti-human sstr 5 polyclonal antibody (all antibodies from Santa Cruz Biotechnology, Santa Cruz, CA, USA), and 1:500 dilution of a mouse anti-human $\operatorname{sstr}_{2}$ polyclonal antibody (Novus Biologicals, Littleton, CO, USA) according to the experiment, in TBS-T containing 3\% BSA. Membranes were washed three times with TBS-T and then incubated for $1 \mathrm{~h}$ at $22{ }^{\circ} \mathrm{C}$ with 1:2000 dilution of HRP-linked anti-rabbit/mouse $\operatorname{IgG}$ (according to the primary antibody), washed as before, and immersed for $0 \cdot 5-1 \mathrm{~min}$ in the chemiluminescence-detection solution. Subsequently, membranes were exposed for $0.5 \mathrm{~min}$ to generate immunoblots. As internal control, membranes used for $\operatorname{sstr}_{1}$ and sstr $_{5}$ expressions were stripped and reprobed with an antitubulin monoclonal antibody (1:2000; 1A2 clone MoAb, Sigma).

Quantification of the digitized bands was performed in three different experiments $(n=3)$ by UN-SCAN-IT software (Silk Scientific, Orem, UT, USA) according to the software instructions. In brief, for each band, the net optical density level was automatically determined by subtracting the background optical level from the total raw optical density level and the mean was calculated. Data were expressed as arbitrary density units and were normalized according to the total amount of each receptor subtype after a $24 \mathrm{~h}$ treatment.

\section{Immunoprecipitation}

LNCaP and Calu-6 membrane receptors $(300 \mu \mathrm{g})$ were immunoprecipitated with a mouse anti-human $\operatorname{sstr}_{2}$ (Novus Biologicals), a rabbit anti-human sstr 5 polyclonal antibody, and a mouse anti-human $\mathrm{D}_{2} \mathrm{R}$ monoclonal antibody (Santa Cruz Biotechnology) in the presence of $20 \mu \mathrm{l}$ protein-A agarose (Sigma-Aldrich) overnight at $4{ }^{\circ} \mathrm{C}$ on a rotating shaker. After washing with lysis buffer, the protein-A-conjugated immunocomplex was boiled for 5 min with sample buffer $(6 \%$ SDS, $0 \cdot 24 \mathrm{M}$ Tris $-\mathrm{HCl} 0.5 \mathrm{M}, \mathrm{pH} 6 \cdot 8,30 \%$ glycerol, $0.3 \mathrm{mg} / \mathrm{ml}$ BPB, $50 \mathrm{mM}$ dithiothreitol) and centrifuged at $1000 \mathrm{~g}$ for $30 \mathrm{~s}$ to denature and separate the immunocomplex from protein-A agarose. Supernatants were subjected to immunoblot analysis as described in the previous section.

\section{Cell proliferation studies}

To estimate proliferating cells in the $\mathrm{S}$ phase of the cell cycle, $15 \times 10^{3}$ cells from both the cell lines were seeded into 96-well plates in a final volume of $200 \mu \mathrm{l} /$ well and incubated at $37^{\circ} \mathrm{C}$ in a humidified $5 \% \mathrm{CO}_{2}$ atmosphere for $48 \mathrm{~h}$. Then, the culture medium was replaced by adding $180 \mu \mathrm{l}$ of the experimental medium (RPMI 1640/2\% FCS for LNCaP cells and DMEM serum-free $0 \cdot 1 \%$ BSA for Calu-6) containing SRIF analogues and the chimeric compound $\left(10^{-9} \mathrm{M}\right)$. After $48 \mathrm{~h}$ (LNCaP) and $24 \mathrm{~h}$ (Calu-6), proliferation was measured by cell counting and by measuring thymidine incorporation after the addition of $1 \mu \mathrm{Ci}$ [methyl- $\left.{ }^{3} \mathrm{H}\right]$-thymidine $\left({ }^{3} \mathrm{H}\right.$-Thy; Amersham) during the last $6 \mathrm{~h}$ of incubation. ${ }^{3} \mathrm{H}-\mathrm{Thy}$ incorporation was determined after collecting cells on glass fibers filter and counting on a scintillation $\beta$-counter. Results were obtained by determining the mean value of at least four experiments in eight replicates and expressed as $\Delta \%$ of the control.

\section{Statistical analysis}

Data were expressed as mean \pm s.D. for cell proliferation and mean \pm s.E.M. for co-immunoprecipitation studies. All data were analyzed by ANOVA to determine the overall differences between the groups, followed by $t$-test $(P<0 \cdot 05$ was considered significant).

The correlation study was performed by using a linear regression analysis and by calculating the determination coefficient $\left(R^{2}\right)$. To minimize variation among different experiments, the results were expressed as relative variation from untreated control value ( $\Delta \%$ of control value). 


\section{Results}

\section{LNCaP cell line}

$D_{2} R$ gene and protein expression We have already reported the SSTR and $\mathrm{D}_{2} \mathrm{R}$ profile in Calu- 6 , as well as the SSTR content in LNCaP (Ferone et al. 2005, Ruscica et al. 2010), hence, before any test we sought to determine the gene and protein expression of $\mathrm{D}_{2} \mathrm{R}$ in $\mathrm{LNCaP}$ cells, by means of RT-PCR and western blot analysis. By using specific oligoprimers, we detected a product of $523 \mathrm{bp}$ corresponding to the $\mathrm{D}_{2} \mathrm{R}$ mRNA. Ribosomal $18 \mathrm{~S}$ was used as internal control for RT-PCR. Moreover, the analysis by immunoblotting of LNCaP cell extracts, using a specific human $\mathrm{D}_{2} \mathrm{R}$ antibody, showed an immunoreactive band of apparent molecular mass of $40 \cdot 5-42.5 \mathrm{kDa}$, depending on protein glycosylation (Fig. 1).

Receptor interaction A weak signal of constitutive receptor dimers was demonstrated on the membranes of LNCaP cell line. In particular, we detected the presence of sstr $_{1} /$ sstr $_{2}$, sstr $_{2} /$ sstr $_{5}, \quad$ sstr $_{5} / \mathrm{D}_{2} \mathrm{R}$, and sstr $_{2} / \mathrm{D}_{2} \mathrm{R}$ complexes (Fig. 2A-D). Treatment with BIM-23704, an sstr $_{1} / \mathrm{sstr}_{2}-$ preferential compound (with a relative lower affinity for $\operatorname{sstr}_{3}$ as well), increased the amount of sstr $_{1}$ co-immunoprecipitated with $\operatorname{sstr}_{2}$ compared with untreated cells $(P<0 \cdot 05$; Fig. $2 \mathrm{~A})$. This compound did not affect the amount of $\operatorname{sstr}_{2} / \mathrm{sstr}_{5}$ complex (Fig. 2B), however, surprisingly, it was also able to increase either the amount of $\mathrm{D}_{2} \mathrm{R}$ co-immunoprecipitated with $\operatorname{sstr}_{5}\left(P<0 \cdot 01\right.$; Fig. 2C) or the amount of $\mathrm{D}_{2} \mathrm{R}$

\section{$\mathrm{D}_{2} \mathrm{R}$ mRNA and protein expression in LNCaPA}

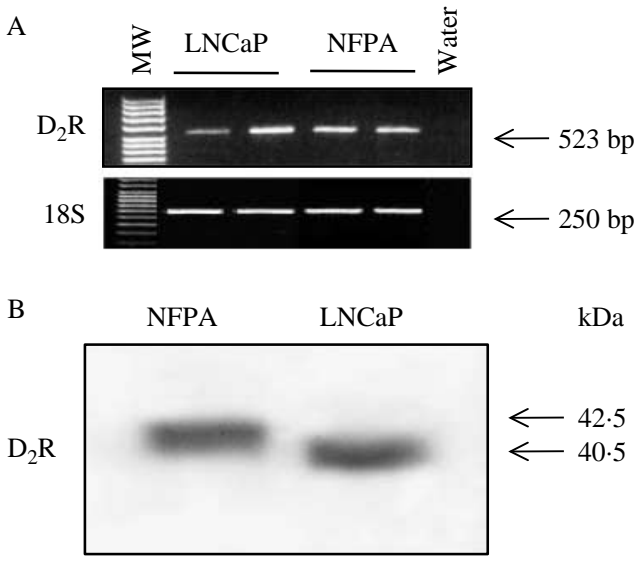

Figure 1 RT-PCR and western blot analysis of $D_{2} R$ expression in LNCaP cells: (A) total RNA extracts from LNCaP cells and nonfunctional pituitary adenoma (NFPA) samples, which served as positive control for $D_{2} R$, were subjected to RT-PCR analysis using oligoprimers specific for $\mathrm{D}_{2} \mathrm{R}$ and $18 \mathrm{~S}$ ribosomal protein (internal control); (B) cell extracts were subjected to western blot analysis using a $D_{2} R$ antibody. Again tissue extract from NFPA was included as positive control. The bands corresponding to $40 \cdot 5-42 \cdot 5 \mathrm{kDa}$ represent two different glycosylated forms of $D_{2} R$. co-immunoprecipitated with $\operatorname{sstr}_{2}(P<0 \cdot 01$; Fig. 2D). Treatment with BIM-23244, a compound with a high affinity for $\operatorname{sstr}_{2}$ and $\operatorname{sstr}_{5}$, significantly increased the amount of $\operatorname{sstr}_{2}$ co-immunoprecipitated with $\operatorname{sstr}_{5}(P<0 \cdot 01$; Fig. $2 \mathrm{~B})$ and the amount of $\mathrm{D}_{2} \mathrm{R}$ co-immunoprecipitated with $\operatorname{sstr}_{5}$ $(P<0 \cdot 01$; Fig. 2C), without affecting the amount of sstr $_{1} /$ sstr $_{2}$ and the $\mathrm{D}_{2} \mathrm{R} /$ sstr $_{2}$ complexes (Fig. $2 \mathrm{~A}$ and $\mathrm{D}$ ). As expected, treatment with BIM-23014, a compound with a high affinity for $\operatorname{sstr}_{2}$ and a relative low affinity for $\operatorname{sstr}_{5}$, increased the amount of $\operatorname{sstr}_{2}$ co-immunoprecipitated with $\operatorname{sstr}_{5}(P<0.05$; Fig. $2 \mathrm{~B})$, but it was also able to increase $\operatorname{sstr}_{1} /$ sstr $_{2} \quad\left(P<0 \cdot 01\right.$; Fig. 2A) and $\mathrm{D}_{2} \mathrm{R} / \mathrm{sstr}_{5}$ complexes $(P<0 \cdot 01$; Fig. 2C). Conversely, this compound did not affect the $\mathrm{D}_{2} \mathrm{R} /$ sstr $_{2}$ complex (Fig. 2D). BIM-23A760, the chimeric $\operatorname{sstr}_{2} / \mathrm{D}_{2} \mathrm{R}$ compound (with a relative high affinity for $\operatorname{sstr}_{5}$ ), was one of the most powerful molecules in increasing the amount of $\mathrm{D}_{2} \mathrm{R}$ co-immunoprecipitated with $\operatorname{sstr}_{5}\left(P<0.01\right.$; Fig. 2C) and the amount of $\mathrm{D}_{2} \mathrm{R}$ co-immunoprecipitated with $\operatorname{sstr}_{2}(P<0 \cdot 01$; Fig. 2D), apparently without influencing the $s \operatorname{str}_{1} / \mathrm{sstr}_{2}$ and $\operatorname{sstr}_{2} / \operatorname{sstr}_{5}$ receptor complexes (Fig. 2A and B). BIM-53097, the $\mathrm{D}_{2} \mathrm{R}$ analogue, displayed a profile similar to that of BIM-23A760 (Fig. 2A-D).

Twenty-four hour treatment with all tested substances did not induce any modification of $\operatorname{sstr}_{1}$ expression (Fig. 2E). Similarly, in line with the results obtained by Froidevaux et al. (1999), either the amount of $\operatorname{sstr}_{2}$ or the amount of $\mathrm{D}_{2} \mathrm{R}$ on cell membrane did not show any difference between untreated and treated cells (data not shown).

Cell proliferation The compounds tested in this study produced different antiproliferative effects, as displayed in Fig. 3. According to the above described ability in inducing SSTR $/ \mathrm{D}_{2} \mathrm{R}$ interaction, the chimeric compound BIM-23A760 showed the highest antiproliferative effect $(42 \cdot 30 \pm 2 \cdot 62 \%$ versus control) compared with the other test molecules. In line with the potential involvement of $\operatorname{sstr}_{1}$ and $\mathrm{sstr}_{3}$ in the pathophysiology of prostate cancer, BIM23704 ( $\operatorname{str}_{1} / \mathrm{sstr}_{2} / \mathrm{sstr}_{3}$-preferential compound) and BIM23926 (sstr 1 monospecific compound) showed a significant antiproliferative effect $(-30 \cdot 98 \pm 6 \cdot 59$ and $-36 \cdot 10 \pm 5 \cdot 58 \%$ versus control respectively). The truly bi-specific $\operatorname{sstr}_{2} / \mathrm{sstr}_{5}$ compound BIM-23244 and the clinically available SRIF analogue lanreotide (BIM-23014) showed a higher antiproliferative effect $(-41 \cdot 36 \pm 4 \cdot 85$ and $-33 \cdot 14 \pm 4 \cdot 60 \%$ versus control respectively) as compared with the monospecific sstr $_{2}$ agonist BIM-23120 alone $(-10 \cdot 89 \pm 5 \cdot 03 \%$ versus control) or in combination with the monospecific sstr 5 agonist BIM-23206 ( $-24 \cdot 18 \pm 4 \cdot 03 \%$ versus control). Treatment with BIM-23206 alone showed the lowest antiproliferative effect $(-9 \cdot 60 \pm 3 \cdot 53 \%$ versus control), whereas the $\mathrm{D}_{2} \mathrm{R}$-preferential compound, BIM-53097, showed a significantly higher antiproliferative effect $(-34 \cdot 4 \pm 7 \cdot 85 \%$ versus control), confirming a crucial involvement of $\mathrm{D}_{2} \mathrm{R}$ activation in the inhibition of cell growth. 
LNCaP-receptor dimerization

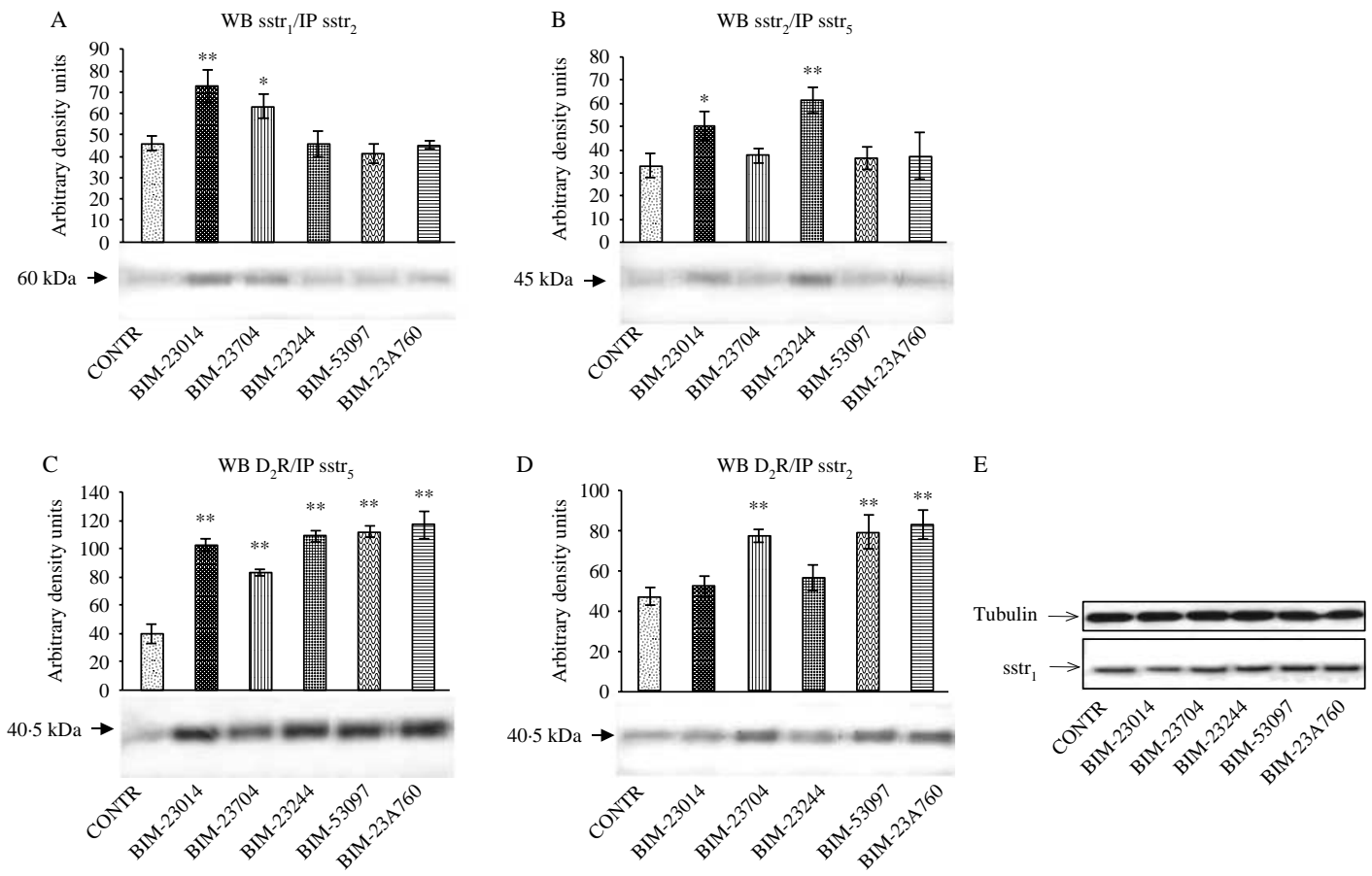

Figure 2 Co-immunoprecipitation studies: glycosylated membrane proteins (300 $\mu \mathrm{g}$ ) obtained after treatment of LNCaP with the SRIF analogues and the chimeric compound $\left(10^{-9} \mathrm{M}\right)$ were analyzed for the presence of receptor dimers. On the top of each panel the histogram represents the densitometric analysis of the corresponding band calculated as mean \pm S.E.M. of three different experiments. On the bottom of each panel a representative immunoblot is shown. (A) Immunoprecipitation of membrane receptors with a mouse anti-human $\operatorname{sstr}_{2}$ antibody and immunoblotting with a rabbit anti-human sstr $_{1}$ antibody (in order to avoid the interference of $\gamma$-globulin with the band corresponding to the $\mathrm{sstr}_{1}$ ). The band corresponding to $60 \mathrm{kDa}$ represents the amount of $\operatorname{sstr}_{1}$ co-immunoprecipitated with sstr $_{2}$.

(B) Immunoprecipitation of membrane receptors with a rabbit anti-human $\operatorname{sstr}_{5}$ antibody and immunoblotting with a mouse anti-human $\mathrm{sstr}_{2}$ antibody. The band corresponding to $45 \mathrm{kDa}$ represents the amount of $\mathrm{sstr}_{2}$ co-immunoprecipitated with $\operatorname{sstr}_{5}$. (C) Immunoprecipitation of membrane receptors with a rabbit anti-human sstr $_{5}$ antibody and immunoblotting with a mouse anti-human $\mathrm{D}_{2} \mathrm{R}$ antibody. The band corresponding to $40 \cdot 5 \mathrm{kDa}$ represents the amount of $D_{2} R$ co-immunoprecipitated with $\operatorname{sstr}_{5}$. (D) Immunoprecipitation of membrane receptors with a rabbit anti-human sstr $_{2}$ antibody and immunoblotting with a mouse anti-human $\mathrm{D}_{2} \mathrm{R}$ antibody. The band corresponding to $40.5 \mathrm{kDa}$ represents the amount of $\mathrm{D}_{2} \mathrm{R}$ co-immunoprecipitated with $\mathrm{sstr}_{2}$. (E) A representative $\mathrm{sstr}_{1}$ immunoblot showing unmodified bands of this receptor after a $24 \mathrm{~h}$ treatment. On the top of the panel a tubulin immunoblot is shown as internal control. WB, western blot; IP, immunoprecipitation; CONTR, control (untreated cells). ${ }^{*} P<0 \cdot 05 ;{ }^{* *} P<0 \cdot 01$.

\section{Calu-6 cell line}

Receptor interaction Similarly to LNCaP, baseline constitutive receptor interactions were demonstrated on the membranes of Calu- 6 cell line as well. In particular, we detected a significant amount of sstr $_{2}$ co-immunoprecipitated with sstr 5 and $\operatorname{sstr}_{5}$ with $\mathrm{D}_{2} \mathrm{R}$ on the membranes of these cells (Fig. 4A and B). Treatment with BIM-23014 (a high affinity for $\operatorname{sstr}_{2}$ and a low affinity for $\operatorname{sstr}_{5}$ ) strongly increased the amount of $\operatorname{sstr}_{2}$ co-immunoprecipitated with $\operatorname{sstr}_{5}(P<0 \cdot 01$; Fig. 4A) without affecting $\operatorname{sstr}_{5} / \mathrm{D}_{2} \mathrm{R}$ and $\operatorname{sstr}_{2} / \mathrm{D}_{2} \mathrm{R}$ interactions (Fig. 4B and C). The bi-specific compound with a high affinity for both $\operatorname{sstr}_{2}$ and $\operatorname{sstr}_{5}$, BIM-23244, increased the amount of $\operatorname{sstr}_{2}$ co-immunoprecipitated with $\operatorname{sstr}_{5}\left(P<0 \cdot 01\right.$; Fig. 4A), as well as $\operatorname{sstr}_{2}$ co-immunoprecipitated with $\mathrm{D}_{2} \mathrm{R} \quad(P<0 \cdot 05$; Fig. $4 \mathrm{C})$. Conversely, BIM-23A760, the chimeric compound, with a high affinity for $\operatorname{sstr}_{2}$ and $\mathrm{D}_{2} \mathrm{R}$, and a moderate affinity for $\operatorname{sstr}_{5}$, significantly increased the amount of both $\operatorname{sstr}_{2}$ co-immunoprecipitated with sstr ${ }_{5}$ and $\operatorname{sstr}_{5}$ co-immunoprecipitated with $\mathrm{D}_{2} \mathrm{R} \quad(P<0.01$; Fig. 4A and $\mathrm{B})$ without affecting $\operatorname{sstr}_{2}$ co-immunoprecipitated with $\mathrm{D}_{2} \mathrm{R}$ (Fig. 2C). BIM-53097, the $\mathrm{D}_{2} \mathrm{R}$-preferential compound, significantly increased the amount of $\operatorname{sstr}_{5}$ co-immunoprecipitated with $\mathrm{D}_{2} \mathrm{R}$ $(P<0 \cdot 01$; Fig. $4 \mathrm{~B})$, as well as $\operatorname{sstr}_{2}$ co-immunoprecipitated with $\mathrm{D}_{2} \mathrm{R}(P<0 \cdot 05$; Fig. $4 \mathrm{C})$. Twenty-four hours treatment with all the tested substances did not induce any modification of sstr $_{5}$ expression (Fig. 4D), as well as $\operatorname{sstr}_{2}$ and $\mathrm{D}_{2} \mathrm{R}$ (data not shown), as already described (Froidevaux et al. 1999).

Cell proliferation The chimeric compound BIM-23A760 resulted significantly more effective in inhibiting cell proliferation compared with all the other compounds, tested 


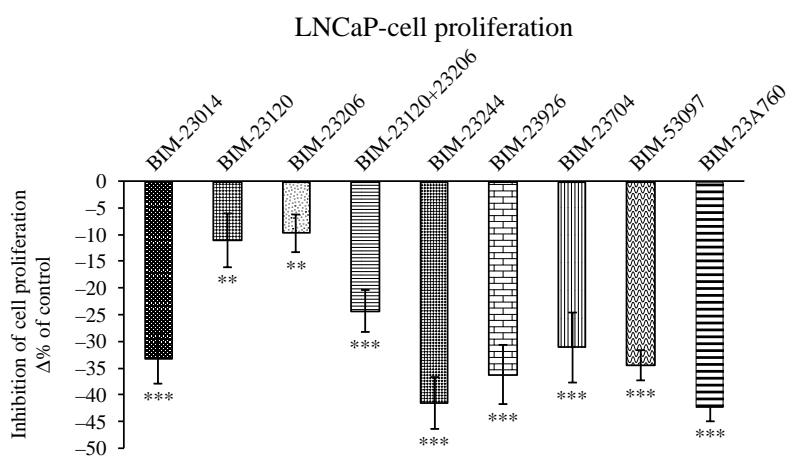

Figure 3 Proliferation studies: $15 \times 10^{3}$ LNCaP cells were seeded into 96-wells plates and incubated for $48 \mathrm{~h}$ with the experimental molecules at a concentration of $10^{-9} \mathrm{M}$ in the presence of

${ }^{3} \mathrm{H}$-Thymidine $(1 \mu \mathrm{Ci})$. Results, obtained from eight replicates of four different experiments, are expressed as percent of cell proliferation (inhibition) \pm S.D. with respect to control (untreated cells). ${ }^{* *} P<0 \cdot 01 ;{ }^{* * *} P<0 \cdot 001$.

alone or in combination $(-30 \cdot 54 \pm 3 \cdot 15 \%$ versus control). BIM-23244, the $\operatorname{sstr}_{2^{-}}$and sstr $_{5}$-preferential compound, resulted as effective as BIM-23014 in inhibiting ${ }^{3} \mathrm{H}$-Thy incorporation $(-15 \cdot 84 \pm 1 \cdot 13 \%$ versus control and $-11 \cdot 64 \pm 2 \cdot 32 \%$ versus control respectively). The $\operatorname{sstr}_{2^{-}}$and

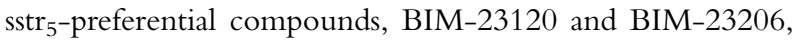
tested alone, did not show a significant inhibition of cell proliferation $(-2 \cdot 25 \pm 1 \cdot 71$ and $-3 \cdot 66 \pm 0 \cdot 08 \%$ versus control respectively), even though these molecules displayed an additive effect $(-7 \cdot 00 \pm 1 \cdot 88 \%$ versus control) when tested in combination (Fig. 5). Confirming an important involvement of $\mathrm{D}_{2} \mathrm{R}$ in the regulation of cell functions, BIM-53097 showed also a significant inhibition of cell proliferation $(-17 \cdot 34 \pm 1 \cdot 95 \%$ versus control).

Correlations We investigated the correlations between receptor interaction and cell proliferation of the treated cells by comparing the ligand-induced receptor co-immunoprecipitation with the inhibition of cell proliferation (both evaluated as $\Delta \%$ of control). The amount of $\mathrm{sstr}_{2}$ co-immunoprecipitated with $\operatorname{sstr}_{5}$ was not correlated $\left(R^{2} 0 \cdot 0003 ; P=0 \cdot 5\right)$ with the inhibition of cell proliferation in both cell lines. Conversely, the amount of $\operatorname{sstr}_{5}$ co-immunoprecipitated with $\mathrm{D}_{2} \mathrm{R}$ was directly and significantly correlated $\left(R^{2} 0 \cdot 87\right.$; $P=0 \cdot 001)$ with the inhibition of cell proliferation in both cell lines (Fig. 6).

\section{Discussion}

Several studies focusing on the effect of SRIF and DA analogues on the control of cell secretion and proliferation have demonstrated a broad profile of action, both in vivo and in vitro, in different tissues besides the neuroendocrine ones (Lamberts et al. 2002, Schally \& Nagy 2003). There are also increasing evidences that SRIF and DA receptors can interact on cell membrane forming homo- or heterodimers with an enhanced functional activity (Ferone et al. 2009). Moreover, almost all studies carried out on cell lines showed receptor dimerization in transfected models highly expressing at least two receptor subtypes (Rocheville et al. 2000a, Pfeiffer et al. 2001, Ren et al. 2003). In this study, we have used two tumor cell lines constitutively expressing four (LNCaP) and three (Calu-6) out of the five SRIF receptors (Ferone et al. 2005, Ruscica et al. 2010) and the $\mathrm{D}_{2} \mathrm{R}$. These non-neuroendocrine cell lines, because of their constitutive and relatively low receptor expression, represent a useful model to investigate the physiological mechanisms involved in protein membrane interaction, such as receptor dimerization. Since recently new SRIF analogues with a specific affinity for given receptor subtypes, and SRIF/DA chimeric compounds have been

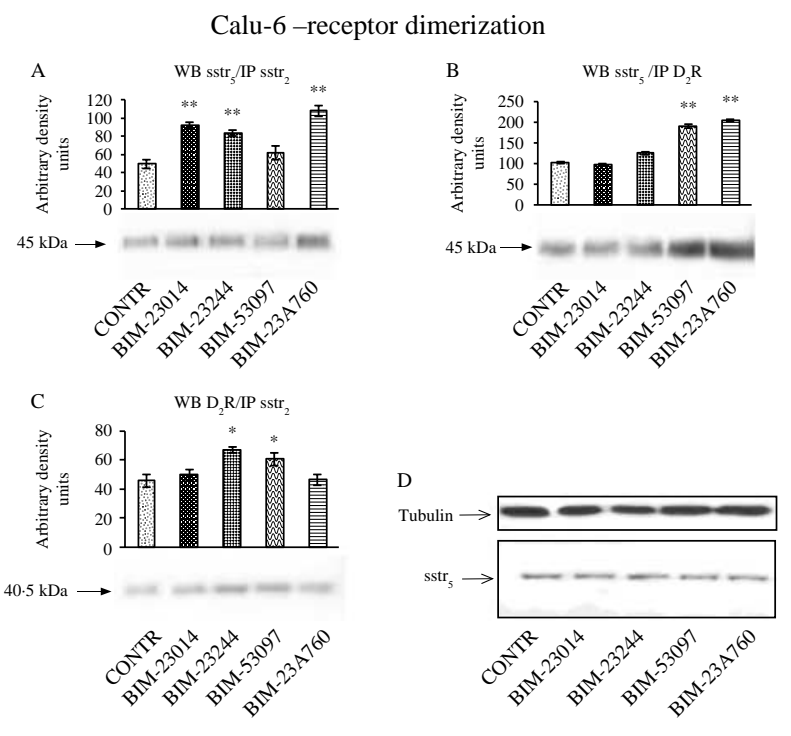

Figure 4 Co-immunoprecipitation studies: glycosylated membrane proteins $(300 \mu \mathrm{g})$ obtained after treatment of Calu- 6 cells with the SRIF and DA analogues and the chimeric compound $\left(10^{-9} \mathrm{M}\right)$ were analyzed for the presence of receptor dimers. On the top of each panel the histogram represents the densitometric analysis of the corresponding band calculated as mean \pm s.E.M. of three different experiments. On the bottom of each panel a representative immunoblot is shown. (A) Immunoprecipitation of membrane receptors with a mouse anti-human sstr $_{2}$ antibody and immunoblotting with a rabbit anti-human $\operatorname{sstr}_{5}$ antibody (in order to avoid the interference of $\gamma$-globulin with the band corresponding to the sstr $_{5}$ ). The band corresponding to $45 \mathrm{kDa}$ represents the amount of $\mathrm{sstr}_{5}$ co-immunoprecipitated with $\mathrm{sstr}_{2}$. (B) Immunoprecipitation of membrane receptors with a mouse anti-human $D_{2} R$ antibody and immunoblotting with a rabbit anti-human $\operatorname{sstr}_{5}$ antibody. The band corresponding to $45 \mathrm{kDa}$ represents the amount of $\operatorname{sstr}_{5}$ co-immunoprecipitated with $\mathrm{D}_{2} \mathrm{R}$. (C) Immunoprecipitation of membrane receptors with a rabbit anti-human $\mathrm{sstr}_{2}$ antibody and immunoblotting with a mouse anti-human $D_{2} R$ antibody. The band corresponding to $40 \cdot 5 \mathrm{kDa}$ represents the amount of $D_{2} R$ Co-immunoprecipitated with $\mathrm{sstr}_{2}$. (D) A representative $\mathrm{sstr}_{5}$ immunoblot showing unmodified bands of this receptor after a $24 \mathrm{~h}$ treatment. On the top of the panel a tubulin immunoblot is shown as internal control. WB, western blot; IP, immunoprecipitation; CONTR, control (untreated cells). ${ }^{*} P<0 \cdot 05 ; * * P<0 \cdot 01$. 


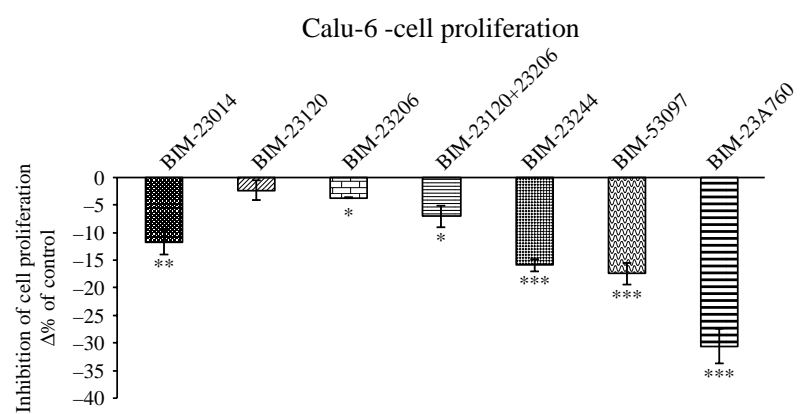

Figure 5 Proliferation studies: $15 \times 10^{3}$ Calu- 6 cells were seeded into 96-well plates and incubated for $48 \mathrm{~h}$ with the experimental molecules at a concentration of $10^{-9} \mathrm{M}$ in the presence of ${ }^{3} \mathrm{H}$-Thymidine $(1 \mu \mathrm{Ci})$. Results, obtained from eight replicates of four different experiments, are expressed as percent of cell proliferation (inhibition) \pm s.D. with respect to control (untreated cells). ${ }^{*} P<0 \cdot 05 ;{ }^{* *} P<0 \cdot 01 ;{ }^{* * *} P<0 \cdot 001$.

developed (Ferone et al. 2005, Saveanu \& Jaquet 2009), in this study we have investigated the effect of these compounds on receptor interaction, and correlated the occurrence of co-immunoprecipitated receptors with the impact on cell proliferation. Since we already demonstrated a dose-response effect of these compounds in the inhibition of cell proliferation (Ferone et al. 2005), in this study, we have performed all experiments using the concentration of compounds that demonstrated about a 50\% inhibitory effect $\left(10^{-9} \mathrm{M}\right)$.

According to the baseline expression of SSTR subtypes in the two cell lines (Ferone et al. 2005, Ruscica et al. 2010) and to the ineffectiveness of a $24 \mathrm{~h}$ treatment on receptor expression, we tested specific SRIF analogues in order to study the different combinations of (potential) receptor interaction. Indeed, in LNCaP cell line, we tested the bi-specific SRIF compounds targeting sstr ${ }_{1}$, sstr 2 , and sstr $_{5}$, and in Calu-6 cell line, the bi-specific SRIF compounds targeting $\operatorname{sstr}_{2}$ and sstr $_{5}$.

Since we have demonstrated the expression of $\mathrm{D}_{2} \mathrm{R}$ in both the cell lines, we also tested the $\operatorname{sstr}_{2} / \mathrm{sstr}_{5} / \mathrm{D}_{2} \mathrm{R}$ chimeric compound and the $\mathrm{D}_{2} \mathrm{R}$ analogue in order to evaluate the involvement of $\mathrm{D}_{2} \mathrm{R}$ in membrane receptor interaction.

The results of western blot and co-immunoprecipitation experiments clearly demonstrated that all SSTRs investigated were able to co-immunoprecipitate with other SSTRs and/or with $\mathrm{D}_{2} \mathrm{R}$. Moreover, the results of this study confirmed the ability of SSTRs and $\mathrm{D}_{2} \mathrm{R}$ to interact on plasma membrane, even in the absence of ligands. On the basis of a strong specificity of the receptors subtype antibodies we used, we considered the co-immunoprecipitated receptor as an expression of the presence of constitutive heterodimer. Moreover, besides observing receptor co-immunoprecipitation in basal conditions, we found that treatment with SRIF analogues and with an SRIF/DA chimeric compound can differently modulate the amount of the potential dimers on plasma membranes.
As far as LNCaP cell line is concerned, all compounds targeting $\operatorname{sstr}_{2}$ showed the ability to increase the interaction between almost all the receptors studied, in particular the interaction between SSTR and $\mathrm{D}_{2} \mathrm{R}$. As a matter of fact, we observed that lanreotide was able to increase the amount of sstr $_{5}$ co-immunoprecipitated with $\mathrm{D}_{2} \mathrm{R}$, as well as BIM23704, despite its prevalent affinity for $\operatorname{sstr}_{1} / \mathrm{sstr}_{2} / \mathrm{sstr}_{3}$. As expected, the chimeric compound BIM-23A760 drastically increased the amount of SSTR co-immunoprecipitated with $\mathrm{D}_{2} \mathrm{R}$, resulting in one of the most effective antiproliferative agents among all tested molecules. This last finding suggests a crucial role of $\mathrm{D}_{2} \mathrm{R}$ in the mechanism involved in the control of tumor growth in these cells, as confirmed by the significant antiproliferative effect and by the increase in the amount of $\operatorname{sstr}_{2}$ co-immunoprecipitated with $\mathrm{D}_{2} \mathrm{R}$ exerted by the monospecific $\mathrm{D}_{2} \mathrm{R}$ compound, BIM-53097. Since the $\operatorname{sstr}_{2}$ monospecific compound failed to display a significant antiproliferative effect, and $\operatorname{sstr}_{1}$ and $\operatorname{sstr}_{3}$, but not $s \mathrm{st}_{2}$, are the receptor subtypes mostly involved in the pathophysiology of prostate cancer, we deduced that $\operatorname{sstr}_{2}$ might mainly function as a 'scaffold' for other receptors in the formation of heterodimers.

As far as Calu-6 cell line is concerned, we observed that sstr $_{2}$ and sstr $_{5}$ receptors exert a role in the inhibition of cell growth only when activated synergistically. This finding is supported by the effect of the $\operatorname{sstr}_{2} / \mathrm{sstr}_{5}$ bi-specific compound, BIM-23244, either in the inhibition of cell growth or in the increase in $\operatorname{sstr}_{2}$ co-immunoprecipitated with sstr. $_{5}$. Moreover, Calu-6 cell line displayed a greater sensibility to the chimeric compounds compared with that observed in LNCaP cells, showing an increase in the amount of sstr $_{5}$ co-immunoprecipitated with $\mathrm{D}_{2} \mathrm{R}$. Moreover, even though the chimeric compound BIM-23A760 was basically ineffective in modulating $s \operatorname{sr}_{2} / \mathrm{D}_{2} \mathrm{R}$ co-immunoprecipitation, it displayed a significant antiproliferative effect. However, considering the affinity of BIM-23A760 for sstr 5 as well, this apparent discrepancy can be explained by the predominant involvement of this latter receptor subtype and of $\mathrm{D}_{2} \mathrm{R}$, instead of $\mathrm{sstr}_{2}$, in this cell line. Indeed, the inhibition

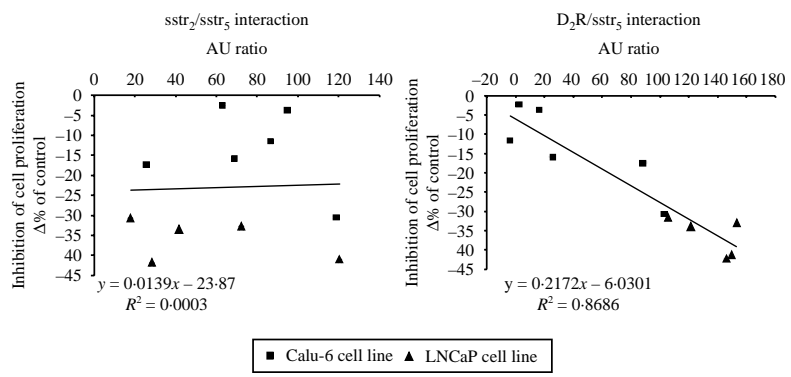

Figure 6 Correlation between $\operatorname{sstr}_{2} / \mathrm{sstr}_{5}$ and $\mathrm{D}_{2} \mathrm{R} / \mathrm{sstr}_{5}$ interaction and cell proliferation in LNCaP (triangles) and Calu-6 (squares). On the $x$-axis the arbitrary density units (AU ratio) of calculated density $(\Delta \%)$ and on the $y$-axis the $\Delta \%$ of thymidine incorporation versus control are reported. The results were obtained by using a linear regression analysis calculating the determination coefficient $\left(R^{2}\right)$. 
of cell proliferation exerted by the $s t_{2}$-preferential compound, BIM-23120, was negligible. This finding is in agreement with the increase in sstr $_{5}$ co-immunoprecipitated with $\mathrm{D}_{2} \mathrm{R}$ induced by BIM-53097 $\left(\mathrm{D}_{2} \mathrm{R}\right.$-preferential compound), supporting again the important role of $\mathrm{D}_{2} \mathrm{R}$ in the induction of SSTR $/ \mathrm{D}_{2} \mathrm{R}$ interaction, probably correlated to the inhibition of cell proliferation as well.

These data highlight the concept of SSTRs as receptors with different functions depending on the different cells in which they are expressed, and not only from the different receptor subtype (Ferone et al. 2001, Zatelli et al. 2001, 2005).

In this study, we have found that the amount of SSTRs co-immunoprecipitated with $\mathrm{D}_{2} \mathrm{R}$ correspond to an enhanced antiproliferative activity. Nevertheless, it remains to be established whether only one receptor of the dimer accounts for the antiproliferative activity, or both receptors (dimer) modulate cell proliferation. Furthermore, we have found that the influence of different dimers on cell proliferation varies in the two different cell types. Dimers with a direct correlation with the antiproliferative effect probably act on the complex cellular system dedicated to the control of cell cycle and apoptosis (Kidd et al. 2008). The evidence that the compounds able to induce receptor dimerization show a strong antiproliferative effect may be partially explained by the cross talk either on the cell membranes, or even at the postmembrane level, of these G-protein-coupled receptor families (Ferone et al. 2009). Indeed, some authors have demonstrated a reduction in receptor internalization rate, due to the ability of one receptor, implicated in the heterodimer, to retain the second receptor on the cell membrane. In this latter phenomenon, an interference with the $\beta$-arrestin system is probably involved (Grant et al. 2008). Another possible explanation of the enhanced antiproliferative action of heterodimers (especially SSR/DR dimers) may be the increased $\mathrm{D}_{2} \mathrm{R}$ activity observed in the cell lines transfected with $\operatorname{sstr}_{2}$ and $\mathrm{D}_{2} \mathrm{R}$ after the treatment with SRIF (Baragli et al. 2007). Studies focused on signal transmission at the postmembrane level showed that SRIF/DA receptor activation (largely $\operatorname{sstr}_{2} / \mathrm{D}_{2} \mathrm{R}$ ) may result in the phosphorylation of c-Jun $\mathrm{N}$-terminal kinase(B) and inhibition of transcription of the cyclin Ki-67, resulting in growth arrest (Kidd et al. 2008).

On the other hand, the presence of enhanced dimers without a direct correlation with cell proliferation sheds light into the complexity of the 'dimer system' that shows a peculiar behavior (far from being completely understood) both at the membrane and postmembrane levels.

In conclusion, the results of this study confirm that the activity of SSTRs and DA receptors could be driven by the specific cell types in which they are expressed, and demonstrate that the dimers behave similarly. Therefore, not only the receptor profiles but also the cell types, as well as the dimerization, are responsible for the final effect of a given ligand. Moreover, in the two cell systems evaluated in this study the only dimer positively correlated with an enhanced antiproliferative effect is the $\operatorname{sstr}_{5} / \mathrm{D}_{2} \mathrm{R}$ one. This finding opens new perspectives for the use of the new chimeric compounds, already used in phase 2 studies in neuroendocrine tumors. However, further studies are warranted to characterize the postreceptor mechanisms involved in the enhanced potency following receptor dimer activation.

\section{Declaration of interest}

MDC is an employer of IPSEN. The other authors have nothing to disclose.

\section{Funding}

This study was supported by grants from Ministero dell'Università e della Ricerca (PRIN 2005 no. 2002067251-001 to FM; Fondo per gli Investimenti della Ricerca di Base no. RBAU019TMF_001 to FM) and Università degli Studi di Milano (FIRST 2007 to PM and PRIN 2007 to MM).

\section{References}

Baragli A, Alturaihi H, Watt HL, Abdallah A \& Kumar U 2007 Heterooligomerization of human dopamine receptor 2 and somatostatin receptor 2 co-immunoprecipitation and fluorescence resonance energy transfer analysis. Cell Signalling 19 2304-2316. (doi:10.1016/j.cellsig.2007. 07.007)

Danila DC, Haidar JN, Zhang X, Katznelson L, Culler MD \& Klibanski A 2001 Somatostatin receptor-specific analogs: effects on cell proliferation and growth hormone secretion in human somatotroph tumors. Journal of Clinical Endocrinology and Metabolism 86 2976-2981. (doi:10.1210/jc.86.7. 2976)

Ferone D, Pivonello R, Lastoria S, Faggiano A, Del Basso de Caro ML, Cappabianca P, Lombardi G \& Colao A 2001 In vivo and in vitro effects of octreotide, quinagolide and cabergoline in four hyperprolactinaemic acromegalics: correlation with somatostatin and dopamine D2 receptor scintigraphy. Clinical Endocrinology 54 469-477. (doi:10.1046/j.1365-2265. 2001.01080.x)

Ferone D, Pivonello R, Van Hagen PM, Dalm VA, Lichtenauer-Kaligis EG, Waaijers M, Van Koetsveld PM, Mooy DM, Colao A, Minuto F et al. 2002 Quantitative and functional expression of somatostatin receptor subtypes in human thymocytes. American Journal of Physiology. Endocrinology and Metabolism 283 E1056-E1066. (doi:10.1152/ajpendo.00205.2001)

Ferone D, Arvigo M, Semino C, Jaquet P, Saveanu A, Taylor JE, Moreau JP, Culler MD, Albertelli M, Minuto F et al. 2005 Somatostatin and dopamine receptor expression in lung carcinoma cells and effects of chimeric somatostatin-dopamine molecules on cell proliferation. American Journal of Physiology. Endocrinology and Metabolism 289 E1044-E1050. (doi:10.1152/ ajpendo.00209.2005)

Ferone D, Saveanu A, Culler MD, Arvigo M, Rebora A, Gatto F, Minuto F \& Jaquet P 2007 Novel chimeric somatostatin analogs: facts and perspectives. European Journal of Endocrinology 156 (Supplement 1) S23-S28. (doi:10. 1530/eje.1.02356)

Ferone D, de Herder WW, Pivonello R, Kros JM, van Koetsveld PM, de Jong T, Minuto F, Colao A, Lamberts SW \& Hofland LJ 2008 Correlation of in vitro and in vivo somatotropic adenoma responsiveness to somatostatin analogs and dopamine agonists with immunohistochemical evaluation of somatostatin and dopamine receptors and electron microscopy. Journal of Clinical Endocrinology and Metabolism 93 1412-1417. (doi:10.1210/jc.20071358)

Ferone D, Gatto F, Arvigo M, Resmini E, Boschetti M, Teti C, Esposito D \& Minuto F 2009 The clinical-molecular interface of somatostatin, dopamine and their receptors in pituitary pathophysiology. Journal of Molecular Endocrinology 42 361-370. (doi:10.1677/JME-08-0162) 
Ferrante E, Pellegrini C, Bondioni S, Peverelli E, Locatelli M, Gelmini P, Luciani P, Peri A, Mantovani G, Bosari S et al. 2006 Octreotide promotes apoptosis in human somatotroph tumor cells by activating somatostatin receptor type 2. Endocrine-Related Cancer 13 955-962. (doi:10.1677/erc.1. 01191)

Florio T 2008 Molecular mechanisms of the antiproliferative activity of somatostatin receptors (SSTRs) in neuroendocrine tumors. Frontiers in Bioscience 13 822-840. (doi:10.2741/2722)

Froidevaux S, Hintermann E, Török M, Mäcke HR, Beglinger C \& Eberle AN 1999 Differential regulation of somatostatin receptor type 2 (sst 2) expression in AR4-2J tumor cells implanted into mice during octreotide treatment. Cancer Research 59 3652-3657.

Grant M, Collier B \& Kumar U 2004a Agonist-dependent dissociation of human somatostatin receptor 2 dimers: a role in receptor trafficking. Journal of Biological Chemistry 279 36179-36183. (doi:10.1074/jbc. M407310200)

Grant M, Patel RC \& Kumar U $2004 b$ The role of subtype-specific ligand binding and the $\mathrm{C}$-tail domain in dimer formation of human somatostatin receptors. Journal of Biological Chemistry 279 38636-38643. (doi:10.1074/ jbc.M406276200)

Grant M, Alturaihi H, Jaquet P, Collier B \& Kumar U 2008 Cell growth inhibition and functioning of human somatostatin receptor type 2 are modulated by receptor heterodimerization. Molecular Endocrinology 22 2278-2292. (doi:10.1210/me.2007-0334)

Kidd M, Drozdov I, Joseph R, Pfragner R, Culler M \& Modlin I 2008 Differential cytotoxicity of novel somatostatin and dopamine chimeric compounds on bronchopulmonary and small intestinal neuroendocrine tumor cell lines. Cancer 113 690-700. (doi:10.1002/cncr.23700)

Lamberts SW, de Herder WW \& Hofland LJ 2002 Somatostatin analogs in the diagnosis and treatment of cancer. Trends in Endocrinology and Metabolism 13 451-457. (doi:10.1016/S1043-2760(02)00667-7)

Møller LN, Stidsen CE, Hartmann B \& Holst JJ 2003 Somatostatin receptors. Biochimica et Biophysica Acta 1616 1-84. (doi:10.1016/S0005-2736(03) 00235-9)

O’Toole D, Saveanu A, Couvelard A, Gunz G, Enjalbert A, Jaquet P, Ruszniewski P \& Barlier A 2006 The analysis of quantitative expression of somatostatin and dopamine receptors in gastro-entero-pancreatic tumours opens new therapeutic strategies. European Journal of Endocrinology 155 849-857. (doi:10.1530/eje.1.02307)

Papotti M, Bongiovanni M, Volante M, Allì E, Landolfi S, Helboe L, Schindler M, Cole SL \& Bussolati G 2002 Expression of somatostatin receptor types 1-5 in 81 cases of gastrointestinal and pancreatic endocrine tumors. A correlative immunohistochemical and reverse-transcriptase polymerase chain reaction analysis. Virchows Archiv 440 461-475. (doi:10. 1007/s00428-002-0609-x)

Patel YC 1999 Somatostatin and its receptor family. Frontiers in Neuroendocrinology 20 157-198. (doi:10.1006/frne.1999.0183)

Patel RC, Kumar U, Lamb DC, Eid JS, Rocheville M, Grant M, Rani A, Hazlett T, Patel SC, Gratton E et al. 2002 Ligand binding to somatostatin receptors induces receptor-specific oligomer formation in live cells. PNAS 99 3294-3299. (doi:10.1073/pnas.042705099)

Pfeiffer M, Koch T, Schröder H, Klutzny M, Kirscht S, Kreienkamp HJ, Höllt V \& Schulz S 2001 Homo- and heterodimerization of somatostatin receptor subtypes. Inactivation of sstr(3) receptor function by heterodimerization with sstr(2A). Journal of Biological Chemistry 276 14027-14036. (doi:10.1074/jbc.M006084200)

Pfeiffer M, Koch T, Schröder H, Laugsch M, Höllt V \& Schulz S 2002 Heterodimerization of somatostatin and opioid receptors cross-modulates phosphorylation, internalization, and desensitization. Journal of Biological Chemistry 277 19762-19772. (doi:10.1074/jbc.M110373200)

Ren SG, Taylor J, Dong J, Yu R, Culler MD \& Melmed S 2003 Functional association of somatostatin receptor subtypes 2 and 5 in inhibiting human growth hormone secretion. Journal of Clinical Endocrinology and Metabolism 88 4239-4245. (doi:10.1210/jc.2003-030303)

Rocheville M, Lange DC, Kumar U, Sasi R, Patel RC \& Patel YC 2000a Subtypes of the somatostatin receptor assemble as functional homo- and heterodimers. Journal of Biological Chemistry 275 7862-7869. (doi:10.1074/ jbc.275.11.7862)

Rocheville M, Lange DC, Kumar U, Patel SC, Patel RC \& Patel YC $2000 b$ Receptors for dopamine and somatostatin: formation of heterooligomers with enhanced functional activity. Science 288 154-157. (doi:10.1126/ science.288.5463.154)

Ruscica M, Arvigo M, Gatto F, Dozio E, Feltrin D, Culler MD, Minuto F, Motta M, Ferone D \& Magni P 2010 Regulation of prostate cancer cell proliferation by somatostatin receptor activation. Molecular and Cellular Endocrinology 315 254-262. (doi:10.1016/j.mce.2009.11.006)

Saveanu A \& Jaquet P 2009 Somatostatin-dopamine ligands in the treatment of pituitary adenomas. Reviews in Endocrine and Metabolic Disorders 10 83-90. (doi:10.1007/s11154-008-9086-0)

Schally AV \& Nagy A 2003 New approaches to treatment of various cancers based on cytotoxic analogs of LHRH, somatostatin and bombesin. Life Sciences 72 2305-2320. (doi:10.1016/S0024-3205(03)00113-9)

Srirajaskanthan R, Watkins J, Marelli L, Khan K \& Caplin ME 2009 Expression of somatostatin and dopamine 2 receptors in neuroendocrine tumours and the potential role for new biotherapies. Neuroendocrinology 89 308-314. (doi:10.1159/000179899)

Weckbecker G, Lewis I, Albert R, Schmid HA, Hoyer D \& Bruns C 2003 Opportunites in somatostatin research: biological, chemical and therapeutic aspects. Nature Reviews. Drug Discovery 2999-1017. (doi:10.1038/nrd1255)

Zatelli MC, Tagliati F, Taylor JE, Rossi R, Culler MD \& degli Uberti EC 2001 Somatostatin receptor subtypes 2 and 5 differentially affect proliferation in vitro of the human medullary thyroid carcinoma cell line tt. Journal of Clinical Endocrinology and Metabolism 86 2161-2169. (doi:10.1210/ jc.86.5.2161)

Zatelli MC, Piccin D, Tagliati F, Bottoni A, Ambrosio MR, Margutti A, Scanarini M, Bondanelli M, Culler MD \& degli Uberti EC 2005 Dopamine receptor subtype 2 and somatostatin receptor subtype 5 expression influences somatostatin analogs effects on human somatotroph pituitary adenomas in vitro. Journal of Molecular Endocrinology 35 333-341. (doi:10.1677/jme.1.01876)

Received in final form 17 September 2010

Accepted 27 September 2010

Made available online as an Accepted Preprint 27 September 2010 